\title{
Sol Amyand herni: Nadir bir olgu
}

\author{
Left sided Amyand Hernia: A very rare case
}

\section{Burak Veli Ülger, Abdullah Oğuz, Eyüp Öner, Enver Ay, Sadullah Girgin}

\section{ÖZET}

Amyand hernisi, fıtık kesesinin içinde Appendiks vermiformisin bulunduğu inguinal herni olarak tarif edilmiştir. Amyand hernisi nadir görülür ve tüm inguinal hernilerin yaklaşık \%1'ini oluşturur. Kese içeriğinin inflame olup olmamasına veya fıtığın boğulup boğulmamasına göre çok farklı klinik tablolara neden olabilir. Yazımızda, sol inguinal herni tanısıyla ameliyat edilen ve fitık kesesinde appendiks vermiformis saptanan 74 yaşındaki bir erkek hastayı sunacağız. Appendiks enflame değildi ve hastanın appendiksi redükte edilip, mesh ile fıtık onarımı yapıldı. Ameliyat sonrası seyir sorunsuzdu. Appendiksin enflame olmadığı Amyand hernilerinde appendektomi yapılması tartışmalıdır. Yine, sol amyand hernilerde ilerde apandisit gelişirse tanı koymadaki zorluktan dolayı, enflame olmasa bile apendektomi önerilmektedir. Biz, hasta ileri yaşta olduğu için apandisit gelişme intimalinin az olması nedeniyle appendektomi yapmadık. Amyand hernilerinin ameliyat öncesi tanısı zor olduğu için hastalara genelde ameliyat sırasında tanı konulmaktadır. Appendektomiye, appendiksin enflame olup olmadığı, fıtığın tarafı, hastanın yaşı ve hastanın komorbiditelerine göre karar verilmelidir.

Anahtar kelimeler: Amyand hernisi, sol taraf, mesh ile onarım

\section{GIRIŞ}

Amyand hernisi ilk kez 1736'da Claudius Amyand tarafından tanımlanmıştır[1]. Fıtık kesesinin içinde Appendiks vermiformis'in bulunduğu inguinal herni olarak tarif edilmiştir. İnguinal hernilerin \%1'inin Amyand Herni'si olduğu saptanmıştır. Vakaların ancak \%0,13'ünde appendiks'in enflame olduğu saptanmıştır [2,3]. Appendiks'in sağ yerleşimli olması, ayrıca inguinal hernilerin de daha çok sağ tarafta oluşması nedeniyle, Amyand hernileri’nin çoğu sağ

\begin{abstract}
An inguinal hernia containing appendix is termed an Amyand's hernia. It is a rare condition estimated to be found in approximately $1 \%$ of all inguinal hernia repairs. Depending on the presence of inflammation in the hernia sac and obstruction of hernia, clinical presentation can vary. We report a case of left sided inguinal hernia in which appendix vermiformis was detected in a 74 year-old male. Appendix was not inflammated, so it was reduced and then mesh hernioplasty was performed. The postoperative course was uneventful. Performing appendectomy is controversial in Amyand hernias in which appendix is not inflammated. Appendectomy is recommended in left sided Amyand hernias, due to the risc of misdiagnosis if appendicitis develops in future. We didn't perform appendectomy because our patient was elderly and had a low risk for developing acute appendicitis. Amyand hernias are usually diagnosed peroperatively. Decision for appendectomy relies on the inflammation of appendix, the side of the hernia, the age and the comorbidities of the patient.
\end{abstract}

Key words: Amyand hernia, left sided, mesh hernioplasty

tarafta görülür [4]. Bu vakaların preoperatif tanısı oldukça zordur ve inkarsere veya strangule herni ile karışabilir [5]. Biz, kliniğimize sol inguinal herni tanısıla yatırılan ve operasyon esnasinda Amyand hernisi tanısı konulan bir vakayı sunacağız.

\section{OLGU}

Yetmiş dört yaşında bir erkek hasta, sol kasıkta beş yıldır olan, son iki aydır büyüyen ve ağrıya neden olan şişlik şikayetiyle polikliniğimize başvurdu. 
Yapılan hazırlıklardan sonra, sol inguinal herni tanisıyla ameliyata alındı. Spinal anestezi ile yapılan ameliyat sirasında, hastanın sol tarafta indirekt inguinal hernisi olduğu saptand1. Spermatik kord askıya alınıp, kese ayrıldı. Fıtık kesesi açıldığında, içinde Appendiks vermiformisin olduğu izlendi (Resim 1). Appendiks normal görünümde idi. Preoperatif çekilen akciğer grafisinde kalp gölgesi ve mide fundus gazı hastanın sol tarafında izlendiği için situs inversus olmadığı teyit edildi (Resim 2).

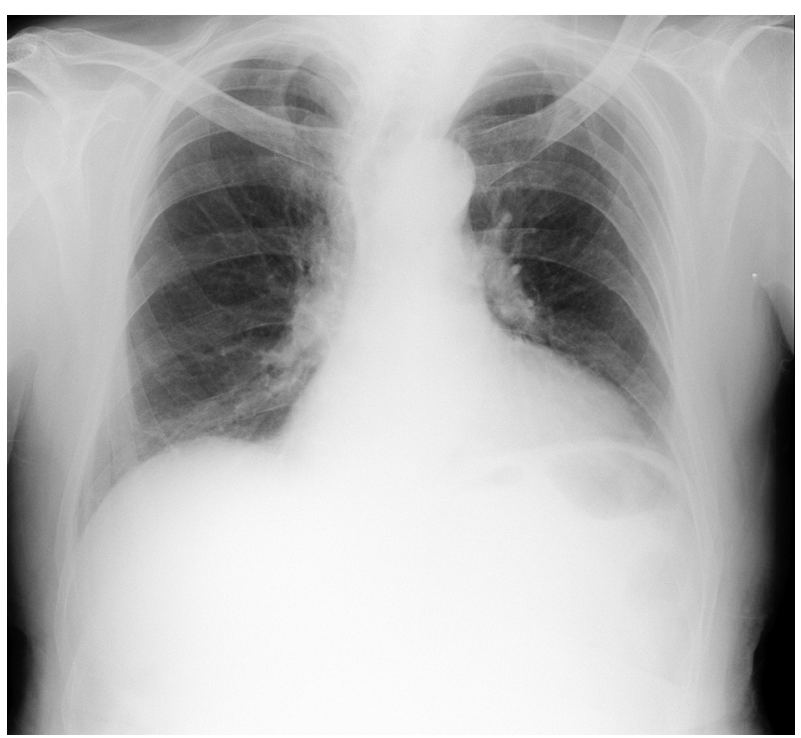

Resim 1. Sol inguinal fıtık kesesi içerisinde saptanan normal görünümlü appendiks vermifomis.

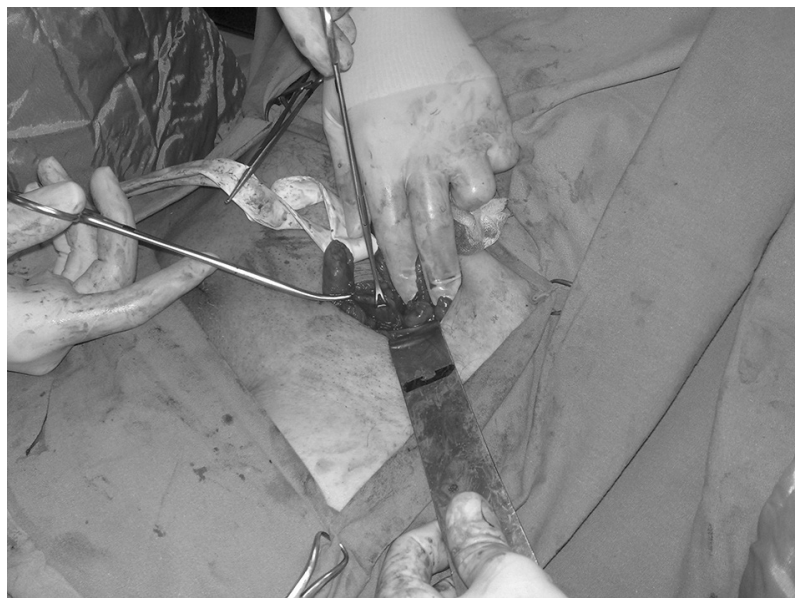

Resim 2. Hastanın ameliyat öncesinde çekilen PA akciğer grafisi. Mide fundus gazının ve kalp gölgesinin sol tarafta olduğu izleniyor.

Sol tarafta Amyand herni oluşması çekumun aşırı mobilize olmasına bağlandı. Hastanın ileri yaşta olması nedeniyle, ilerde apandisit gelişme riskinin az olduğu düşüncesiyle appendektomi yapılmadı. Appendiks redükte edilip, hernisi mesh ile onarıld1. Ameliyat sonrasında hastada herhangi bir problem gelişmedi. Hasta postoperatif 1. günde taburcu edildi.

\section{TARTIŞMA}

Amyand hernisi tanısını koymak zordur. Çoğu vakada, appendiks ancak kese açıldıktan sonra fark edilir. Eğer appendiks enflame ise, inkarsere veya strangule fitıkla, veya skrotum patolojileriyle karıştırılabilir. Tedavisinin düzenlenmesi amacıyla yaptıkları sinıflamada, Losanoff ve Basson, Amyand hernisini 4 tipe ayırmışlardır [6]. Bu sınıflamaya göre Tip 1 hernilerde appendiks normal, tip 2 hernilerde akut appandisit mevcut ancak enflamasyon kesede sinırlı, tip 3 hernilerde akut appandisit peritonit'e neden olmuş, tip 4 hernilerde ise, akut appandisit ile beraber başka abdominal patolojiler de mevcuttur. Fitık kesesi içinde akut appandisit saptanan hastalarda, appendektomi sonrasinda fitık onarımının sentetik mesh ya da plug kullanılmadan yapılması çoğu cerrah tarafından kabul gören bir yaklaşım iken [6], fitık kesesi içinde normal bir appendiks saptanması durumunda, enfeksiyon riskinden kaçınmak için, appendektomi önerilmemektedir [2,7]. Bununla beraber, sol tarafta yerleşen Amyand hernilerde, ilerde akut apandisit gelişirse, tanı koymada zorluk yaşanabileceği için, appendiks enflame olmasa da appendektomi yapılmasinı önerenler de vardır [4]. Bizim hastamızda, sol Amyand hernisi vard 1 ve appendiks enflame değildi. Ancak biz, hastanın 74 yaşında olmasını göz önüne alarak, ilerde akut apandisit gelişme ihtimalinin nispeten az olduğu düşüncesiyle appendektomi yapmadık. Fit1ğ için mesh ile onarım ihtiyacı olan hastada, kontaminasyon riski de, appendektomi yapmamamızın diğer bir nedeniydi.

Sonuç olarak, nadir görülen bir fitık olduğu gibi, preoperatif tanısının da çok zor olması nedeniyle, Amyand hernilerinin tanısı çoğu zaman ancak ameliyat sırasında konulmaktadır. Bu yüzden tedavi yöntemine de ameliyat sırasında karar vermek gerekmektedir. Tedavi yönteminin seçiminde, Appendiksin enflame olup olmadığı, hastanın yaşı ve komorbiditesinin olup olmadığ 1 gibi faktörler göz önünde bulundurulmalıdır. 


\section{KAYNAKLAR}

1. Losanoff JE, Basson MD. Amyand hernia: what lies beneath -a proposed classification scheme to determine management. Am Surg 2007;73:1288-1290.

2. House MG, Goldin SB, Chen H. Perforated Amyand's hernia. South Med J 2001;94:496-498.

3. Sharma H, Gupta A, Shekhawat NS, et al. Amyand's hernia: A report of 18 consecutive patients over a 15 -year period. Hernia 2007;11:31-35.
4. Johari HG, Paydar S, Davani SZ, et al. Left-sided Amyand hernia. Ann Saudi Med 2009;29:321-322.

5. Mishra VK, Joshi P, Shah JV, et al. Amyand's Hernia: A Case of an Unusual Inguinal Herniace. Indian J Surg 2013;75:469-471

6. Losanoff JE, Basson MD. Amyand hernia: a classification to improve management. Hernia 2008;12:325-326.

7. D'Alia C, Lo Schiavo MG, Tonante A, et al. Amyand's hernia: case report and review of the literature. Hernia 2003;7:89-91. 